\title{
Blepharophimosis sequence and diaphragmatic hernia associated with interstitial deletion of chromosome 3 (46,XY, del(3)(q21q23))
}

\author{
J Wolstenholme, J Brown, K G Masters, C Wright, C J English
}

\begin{abstract}
A case of blepharophimosis, ptosis, and epicanthus inversus (BPES) associated with prenatally diagnosed diaphragmatic hernia and interstitial deletion of the long arm of chromosome 3, del(3)(q21q23), is reported. Comparison with other cases of BPES resulting from 3q rearrangements indicate that this disorder, previously assigned to $3 \mathrm{q} 2$, can now be more accurately mapped to 3q23.
\end{abstract}

( $\mathcal{f}$ Med Genet 1994;31:647-648)

The association of blepharophimosis, ptosis, and epicanthus inversus (BPES) with structural rearrangements of $3 \mathrm{q}$ has been reported for both familial ${ }^{1}$ and de novo ${ }^{23}$ translocations and several interstitial deletions, ${ }^{4-10}$ including one forming part of a complex de novo rearrangement involving two other chromosomes ${ }^{7}$ and one derived from a familial inserted translocation. ${ }^{8}$ We report a further case of a small de novo interstitial deletion resulting in the classic features of BPES complicated by diaphragmatic hernia detected prenatally. The missing chromosome segment can be unequivocally defined, having only minimal overlap with several previously described deletions, allowing BPES to be mapped conclusively to $3 \mathrm{q} 23$.

\section{Case report}

Ultrasound examination of the fetus of a 25 year old primigravida showed an appearance suggestive of diaphragmatic hernia at 18, 19.5, and 24 weeks' gestation. Lymphocyte chromosome preparations from a cordocentesis sample taken at 24 weeks' gestation showed a small interstitial

Genetics Service, Department of

Human Genetics,

University of

Newcastle upon Tyne,

20 Claremont Place,

Newcastle upon Tyne

NE2 4AA, UK

J Wolstenholme

J Brown

K G Masters

C J English

Division of Pathology, University of

Newcastle upon Tyne, The Royal Victoria Infirmary, Newcastle upon Tyne NE1 4LP, UK

C Wright

Correspondence to Dr Wolstenholme.

Received 10 February 1994 Revised version accepted for publication 3 March 1994

Figure 1 Interstitial deletion of chromosome 3q. deletion of the long arm of chromosome 3 involving loss of $3 \mathrm{q} 22$ and proximal q23, namely 46,XY, del(3)(q21q23) (fig 1). Both parents had normal karyotypes. The pregnancy was terminated at 25 weeks' gestation. Necropsy showed a male fetus, weight $728 \mathrm{~g}$, foot length $50 \mathrm{~mm}$, crown-rump length $235 \mathrm{~mm}$, head circumference $215 \mathrm{~mm}$ (consistent with 25 weeks' gestation), with the facial features of BPES (fig 2), telecanthus (inner canthal measurement $20 \mathrm{~mm}$, expected $15 \mathrm{~mm}$ ), shortening of the palpebral fissures $(10 \mathrm{~mm}$, expected 13-14 mm), and a beaked nose. There were no upper eyelid folds. Internally, the left hemidiaphragm was almost entirely absent, with the stomach, most of the left lobe of the liver, and loops of the small and large bowel in the thoracic cavity. No other abnormalities were noted. The fetal karyotype was confirmed in cells cultured from placental villi. A cell line, reference F93/0233, is available from this laboratory.

\section{Discussion}

BPES is most commonly encountered as either a new mutation or in families with autosomal dominant inheritance. ${ }^{11}$ There are probably two distinct but related subtypes of the inherited form: type I, the most common, transmitted by males, where affected females are infertile, and type II, transmitted by both males and females. ${ }^{12}$ This variable phenotype has been interpreted as evidence for BPES being a contiguous gene syndrome. ${ }^{13}$ Several reports $^{1-10}$ of the distinctive facial features of this condition associated with structural rearrangements involving $3 \mathrm{q} 2$ suggest this region as the likely location of both the sporadic and dominant inherited forms of the disorder.

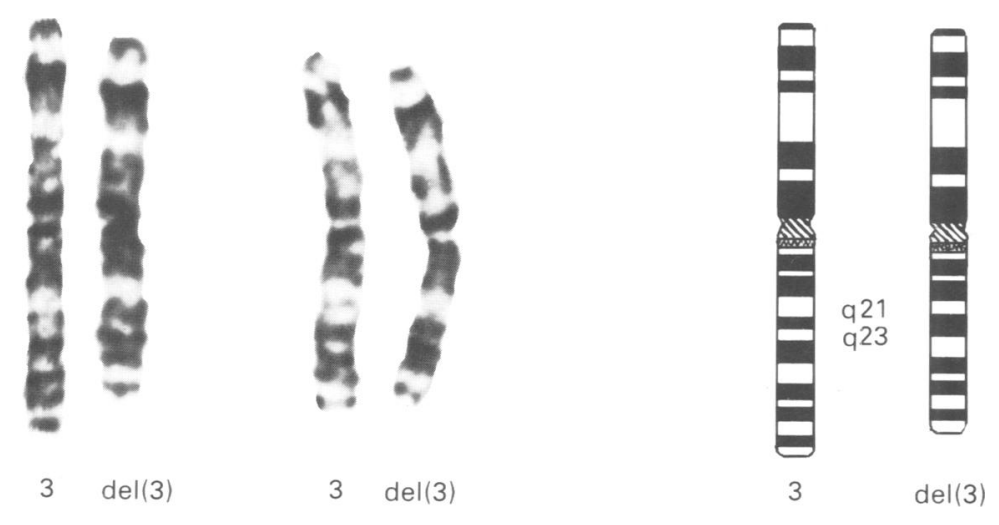



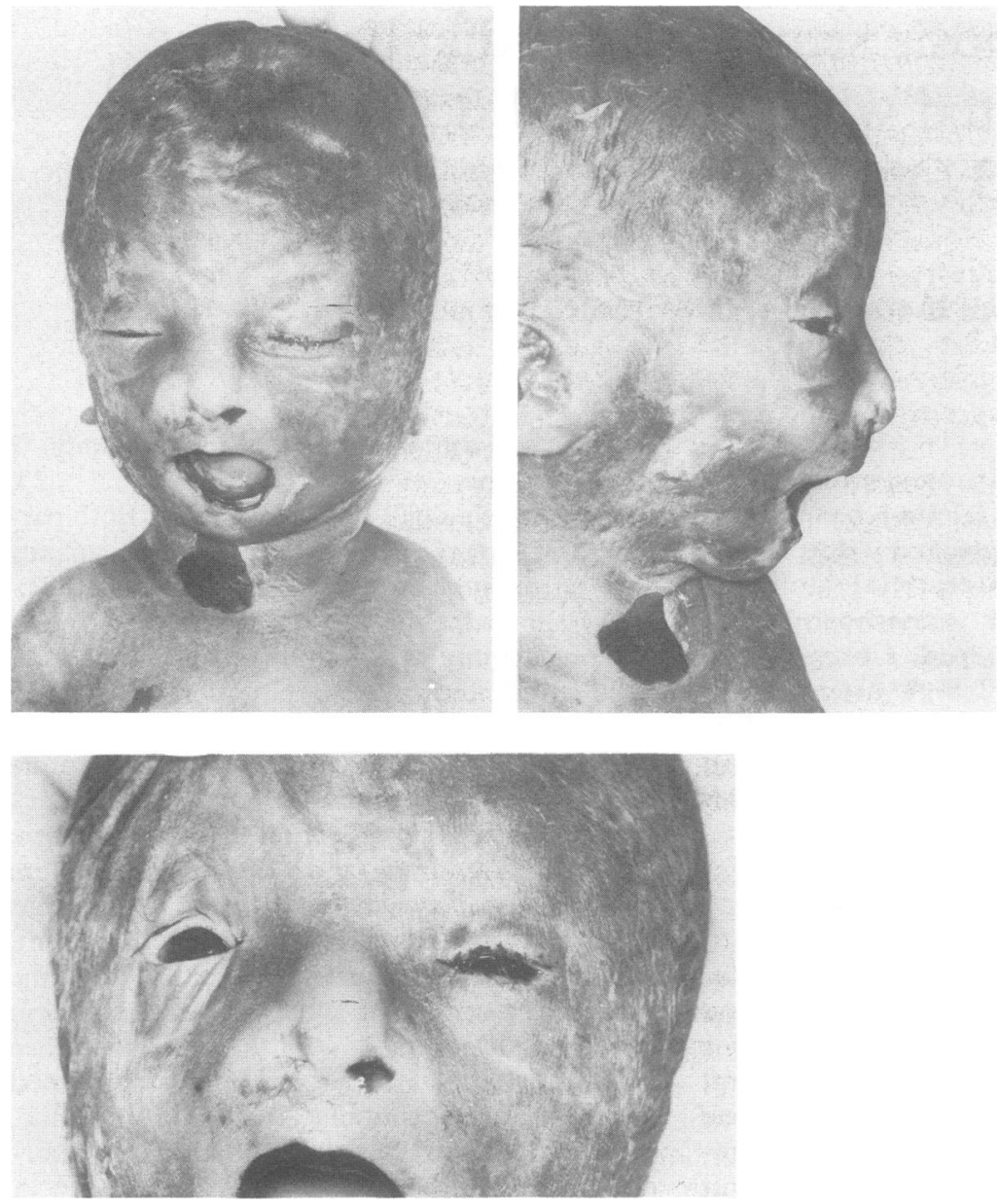

Figure 2 The fetus before necropsy showing facial features of BPES.

There remains, however, some ambiguity as to detailed mapping within $3 \mathrm{q} 2$, owing to the restricted resolution observable in some of the published partial karyotypes, the descriptive limitations of ISCN for microdeletions, and the potential for reinterpretation of breakpoints.

The present case, and those of Williamson et $a l^{8}$ and Fryns et $a l,{ }^{9}$ show the unequivocal loss of a common segment involving bands q22-23, with the deleted chromosomes having very similar appearances in spite of minor variations in interpretation of breakpoints. Three more distal deletions reported by Alvarado et al, ${ }^{5}$ Martsolf and Ray, ${ }^{6}$ and Al-Awadi et $a l,{ }^{7}$ all involve bands q23-25. The minimal area of overlap is thus within q23, which corresponds well with a de novo rearrangement, $46, \mathrm{XY}, \mathrm{t}(3 ; 4)$ (q23;p15.2) observed by Fukushima $e t a l^{2}$ and a $46, \mathrm{XX}, \mathrm{t}(3 ; 8)(\mathrm{q} 23 ; \mathrm{p} 21.1)$ karyotype described by Cabral de Almeida et $a l^{3}$ Jewett et $a l^{10}$ reported a smaller deletion involving loss of q22 only, which they interpreted as placing the gene at the q22-23 boundary, but unfortunately this publication is an abstract without a photograph for comparison.
Two reports, however, suggest a more proximal location on 3q. De Die-Smulders et $a l^{1}$ reported a father and son with typical BPES, both with $46, \mathrm{XY}, \mathrm{t}(3 ; 11)$ (q21;q23) karyotypes, although the quality of the published photograph is not incompatible with alternative breakpoints at 3q23 and 11q25. The case of Fujita $e t a l^{4}$ is less helpful. The authors claim to show an interstitial deletion, $\operatorname{del}(3)(\mathrm{q} 12 \mathrm{q} 23)$, but if this patient has a simple deletion, then the breakpoints indicated on their photograph would be q12 and q21 (not q23), although q23 is arrowed on their ideogram. Again the quality of the published photographs is not incompatible with alternative breakpoints and it is not possible to exclude a more complex rearrangement of 3q.

We interpret these data as indicating location of BPES within 3q23, with preference for the more proximal part of that band. The unusual presentation, in our case, of diaphragmatic hernia detected prenatally has not been associated with other published examples of $3 \mathrm{q}$ deletions with BPES and is not a feature of the familial form of the disorder.

Recognition of further cytogenetic microdeletions involving 3q23, particularly the q22 interface, will allow the localisation of a minimal region of overlap and the eventual molecular identification of the contiguous gene sequence whose deletion or loss of function is responsible for BPES.

1 De Die-Smulders CEM, Engelen JJM, Donk JM, Fryns JP. Further evidence for the location of the BPES gene at $3 q 2$ Further evidence for the locat

2 Fukushima Y, Wakui K, Nishida T, Ueoka Y. Blepharophimosis sequence and de novo balanced autosomal transmosis sequence and de novo balanced autosomal translocation $[46, X Y, t(3 ; 4)(q 23 ; p 15.2)]:$ possible assignm
the trait to 3q23. Am 7 Med Genet 1991;40:485-7.

3 Cabral de Almeida JC, Llerena JC, Neto JBG, Jung $M$, Martins RR. Another example favouring the location of BPES at 3q2. $\mathcal{f}$ Med Genet 1993;30:86.

4 Fujita $H$, Meng J, Kawamura M, Tozuka N, Ishii $F$ Tanaka N. Boy with a chromosome del(3)(q12q23) and blepharophimosis syndrome. Am $\mathcal{f}$ Med Genet 1992;44:434-6.

5 Alvarado M, Bocian M, Walker AP. Interstitial deletion of chromosome 3: case report, review, and definition of phenotype. Am f Med Genet 1987;27:781-6.

6 Martsolf JT, Ray M. Interstitial deletion of the long arm of chromosome 3. Ann Genet (Paris) 1983;26:98-9.

7 Al-Awadi SA, Naguib KK, Farag TI, et al. Complex translocation involving chromosomes $\mathrm{Y}, 1$, and 3 resulting in deletion of 3q23 $\rightarrow \mathrm{q} 25$. $\mathcal{f}$ Med Genet 1986;23:91-2.

8 Williamson RA, Donlan MA, Dolan CR, Thuline HC, Harrison MT, Hall JG. Familial insertional translocation of a portion of $3 \mathrm{q}$ into $11 \mathrm{q}$ resulting in duplication and of a portion of $3 \mathrm{q}$ into $11 \mathrm{q}$ resulting in duplication and Mel Genet 1981;9:105-11.

9 Fryns JP, Stromme P, van de Berghe $H$. Further evidence for the location of the blepharophimosis syndrome (BPES) at the location of the blepharophimosis synd

10 Jewett T, Rao PN, Weaver RG, Stewart W, Thomas IT, Pettenati MJ. Blepharophimosis syndrome (BPES) associated with del 3q22: gene assignment to the interface of band 3q22-q23. Am fु Hum Genet 1992;51(suppl):A81

11 Oley CA, Baraitser M. Blepharophimosis, ptosis, epicanthus inversus syndrome (BPES syndrome). $\mathcal{F}$ Med Genet 1988;25:47-51.

12 Zlotogora J, Sagi M, Cohen T. The blepharophimosis ptosi and epicanthus inversus syndrome: delineation of two types. Am $\mathcal{F}$ Hum Genet 1983;35:1020-7.

13 Smith A, Fraser IS, Shearman RP, Russell P. Blepharophimosis plus ovarian failure: a likely candidate for a contiguous gene syndrome. $\mathcal{F}$ Med Genet 1989;26:434-8. 